\title{
COVID-19 in Low-Middle Income Setting Of Central America Four Region: Limitations on Prevention, Diagnosis, Management and Economic Implications
}

Eleazar Enrique Montalvan Sanchez*, Dalton Argean Norwood and Noelia Andrea Molina Castro Western Honduras Hospital, Copán, Honduras

*Corresponding Author: Eleazar Enrique Montalvan Sanchez, Santa Rosa de Copa, Copan, Honduras. Email: montalvan214@gmail.com Received date: June 26, 2020; Accepted date: July 30, 2020; Published date: August 03, 2020

Citation: Eleazar Enrique Montalvan Sanchez, Dalton Argean Norwood and Noelia Andrea Molina Castro. The Ploc_Bal-Mhum COVID-19 in Low-Middle Income Setting Of Central America Four Region: Limitations on Prevention, Diagnosis, Management and Economic Implications. J Clinical Research Notes, 1(3); DOI:10.31579/2690-8816/025

Copyright: (c) 2020 Eleazar Enrique Montalvan Sanchez. This is an open access article distributed under the Creative Commons Attribution License, which permits unrestricted use, distribution, and reproduction in any medium, provided the original work is properly cited.

\section{Introduction}

The outbreak of novel coronavirus 2019 has spread rapidly; starting in Wuhan China, reporting a cluster of cases of Pneumonia associated with 2019-nCoV on December 31, 2019 [1]. Now with confirmed cases around the world, approximately 128 of 195 countries in total. By the end of January 2020, the World Health Organization declared the current COVID-19 epidemic a Public Health Emergency of International Concern (PHIC) along with the first confirmed case in the United States.

As of March 11, 2020, the coronavirus disease pandemic has reached 174,961 cases (81032 in main-land china) with 6,705 deaths $(3.8 \%)$ and 77,658 reported as recovered [2]. This same date the first two cases of 2019-nCoV were confirmed in Honduras, a Central American country, being the third country affected in this region and the fourteenth in Latin America. Both of them are local females, who entered the country on march fourth and fifth via two different airports on the main cities (Tegucigalpa and San Pedro Sula); flights arriving from Spain and Switzerland respectfully [3].

One of the confirmed cases of 2019-nCoV is a 42-year-old pregnant woman who entered the country through the Toncontín International Airport from Spain. The second patient is a 37-year-old female who arrived at the Ramón Villeda Morales Airport on San Pedro Sula. Four days after the detection of the first two cases in Honduras 4 other cases have been diagnosed. Two of them were in contact with the first infected subject. These two international airports account for all the international flights entering or leaving the country. There also has to be taken into consideration passengers entering the country via maritime and road transport.

Relations between Taiwan and Honduras have always been close. China is one of Honduras leading commercial partners, hence the increasing activity of traveling back and forth between the countries through which severe acute respiratory syndrome coronavirus could easily be propagated in the continent. Now, considered a pandemic, the risk of transmission is having contact with a symptomatic person from a region with confirmed cases.

The ability to limit and control local transmission after introduction of the virus depends on the application and execution of strict measures of detection, prevention, and control. It was expected from Taiwan to have the highest second number of cases of coronavirus disease 2019 due to its proximity to mainland China and to its previous history of SARS epidemic in 2003. But the following actions implemented by Taiwan are helping to manage the crisis, such as: border control, case identification, quarantine of suspicious cases, proactive case finding, resource allocation reassurance and education of the public while fighting misinformation, negotiation with other countries and regions, formulation of policies towards schools and childcare and relief to businesses. All of these actions result from the crisis of the 2003 epidemic of SARS which spread rapidly against an inexperienced and vulnerable government. This nation is an example of how a government can respond quickly to a crisis and protect its citizens interests [4].

\section{Discussion}

These are the first two cases of COVID-19 in Honduras with a population of over 9,265,067 million people. Since this disease is highly contagious, strict and expedite measures have to be taken to control the transmission of the 2019-nCoV. This region is characterized by multiple annual outbreaks of infections which are declared PHIC by WHO (Dengue virus, Zika Virus and Chick Virus).

To date Dengue continues to be a public health problem in the Americas despite the efforts of the government to contain it. Some of the conditions that contribute to its increasing number of cases are: Urban development, rapid mass movement of people and favorable weather conditions. The only method to control transmission is to fight mosquitoes, requiring the active participation of its citizens; one of the strongest measurements to contain diseases.

Before 2019-nCoV the other respiratory virus with epidemic characteristics affecting Honduras is Influenza H1n1, with the majority of cases in Ca-4. As of epidemiological week, 30, 2019 of 634 suspicious samples of Influenza 105 were positive, representing 16.6\%. Influenza associated Pneumonia goes to approximately 936 cases per week. This is important to mention considering the association between 2019-nCoV and cases of complicated pneumonia mostly on the economically active population [5].

The burden that will be imposed on the region, if and when COVID-19 spreads, would be an additional challenge for the healthcare system and economy in the country. Up to date in the tourism sector there are more than 90 percent cancellations, including hotels. Being this sector one of the most important contributing to the country's economy. 
The Healthcare system in Honduras is labile, and resource- limited. However, up to March 16, 2020 Honduran Congress approved over a thousand million dollars to combat the novel 2019-nCov, this is ten times over the healthcare budget for 2019. Budget aimed for the construction of hospitals and clinics to attend isolated care of these patients and the hiring of health personnel. With the local labile economy, lack of healthcare capacity to contain 2019-nCov, the political instability and the expected Dengue virus outbreak in the following months, the Central American resource limited setting is going to have some serious implications in economy and healthcare

\section{Bibliography:}

1. L. Phelan A., Katz R., O. Hosting L. (2020) The Novel Coronavirus Originating in Wuhan, China. Challenges for Global Health Governance. JAMA volume 323, number 8.

2. Dong, E., Du, H., \& Gardner, L. (2020). An interactive webbased dashboard to track COVID-19 in real time. The Lancet Infectious Diseases. doi: 10.1016/s1473-3099(20)30120-1

3. (2020). BBC News -Mundo, Coronavirus: Cuba y Honduras confirman sus dos primeros casos de Covid 2019

4. Wang C. J., Robert C. Y, H. Brook R. (2020) Response to COVID -19 in Taiwan: Big Data Analytics, New Technology and Proactive Testing. JAMA DOI: 10.1001/jama.2020.3151

5. Biblioteca Virtual de Salud ( 04/08/2020) Boletín Informativo. Volumen 40, Semana Epidemiológica 30. 